http://dx.doi.org/10.30681/23588403v12i03141155

\title{
LETRAMENTO(S) NA CONTEMPORANEIDADE: DESENVOLVENDO HABILIDADES DE LEITURA CRÍTICA PARA A INCLUSÃO DIGITAL
}

\author{
Elisa MATTOS (UNL/UFMG) ${ }^{1}$
}

Data de recebimento: $22 / 10 / 2019$

Aceite: 26/11/2019

\begin{abstract}
Resumo: este artigo discute o conceito de letramento, associando-o ao letramento crítico (FREIRE, 1979, 1980, 1987, 2011, 2014). Nosso principal pressuposto é que simplesmente aprender a ler e escrever não resulta necessariamente na aquisição de conhecimentos e/ou estratégias para participar da sociedade de forma crítica. Portanto, o letramento é o resultado de estar imerso nas práticas da língua(gem) (SOARES, 1998), centrada, mas não restritas ao código escrito, isto é, outros modos semióticos, como a fala e (outras) formas multimodais de expressão (KRESS, 2003; 2010) devem ser considerados. Assim, ser letrado significa usar a língua(gem) efetivamente para entender e transformar a realidade, o que implica uma visão de língua(gem) como processo/produto sócio-histórico (BAKHTIN/VOLOSHINOV, 2006). A noção de letramento preconizada neste artigo também dialoga com os letramentos digitais (DUDENEY; HOCKLY; PEGRUM, 2014), dada a predominância das tecnologias digitais na comunicação contemporânea. Nosso objetivo final com este artigo é oferecer aos professores um plano didático para desenvolver a leitura crítica e promover a inclusão digital. Dessa forma, o plano ancora-se em uma visão da leitura engajada, com foco em aprender a ler e ler para aprender (ALEXANDER, FOX, 2013).
\end{abstract}

Palavras-chave: Letramento. Letramento crítico. Letramentos digitais. Leitura crítica.

\begin{abstract}
FREIRE, 1979, 1980, 1987, 2011, 2014). The main assumption is that simply learning how to read and write does not necessarily result in acquiring the knowledge/strategies to take part in society in a critical way. Literacy is therefore understood as the result of being immersed in language practices (SOARES, 1998) centered on, but not limited to, the written word, which means that other semiotic modes, such as speech and (other) multimodal forms of expression (KRESS, 2003; 2010) should be considered as equally important elements of literacy. Being literate means using language effectively to understand and ultimately transform reality. This entails an understanding of language as a socio-historical process/product of human activity (BAKHTIN/VOLOSHINOV, 2006). The notion of literacy assumed in this paper also dialogs with digital literacies (DUDENEY; HOCKLY; PEGRUM, 2014), given the predominance of digital technologies in contemporary communication. Our ultimate purpose with this paper is to offer teachers a teaching plan to develop critical reading and to foster digital inclusion. As such, the teaching plan provided is anchored on a view of engaged reading, with a focus on learning to read and reading to learn (ALEXANDER, FOX, 2013).
\end{abstract}

Keywords: Literacy. Critical literacy. Digital literacies. Critical reading.

\section{Introdução}

A leitura é uma das principais tarefas na formação escolar/acadêmica nas sociedades letradas. No Brasil, as práticas de ensino são essencialmente organizadas por meio de textos escritos, como, por exemplo em livros didáticos. É através da leitura que conhecimentos são construídos em nosso modelo de escola. Assim, aprender a ler (e a escrever) significa ganhar

\footnotetext{
${ }^{1}$ Mestre em Didática de Inglês, Universidade NOVA de Lisboa, Lisboa, Portugal. Doutoranda em Linguística, Universidade Federal de Minas Gerais, Belo Horizonte/MG, Brasil. mattos.elisa@gmail.com.
} 
acesso ao mundo letrado. No entanto, como bem argumenta Freire (1976), saber decodificar a palavra escrita é somente o início de um processo que dura toda a vida: o letramento.

A importância do letramento pode ser justificada tanto pelos resultados medianos da educação brasileira em termos de leitura e interpretação, na faixa dos 40\% (BRASIL, 2016) de acordo com o Programa Internacional de Avaliação de Estudantes - PISA, em comparação à média de 60\% dos países da Organização para a Cooperação e Desenvolvimento Econômico - OCDE, quanto pelas abismais condições de participação brasileira ${ }^{2}$ na crescente adesão às tecnologias digitais na comunicação e educação contemporânea.

Este trabalho reflete sobre o letramento como um elemento-chave para a formação de sujeitos críticos, oferecendo um plano didático para a prática da leitura. Após problematizar o conceito de letramento, tecemos observações acerca do letramento crítico e dos letramentos digitais, seguidas de uma discussão sobre o processo de leitura e, então, apresentamos o plano didático, acompanhado de comentários. Considerações acerca dos temas abordados concluem o presente texto.

\section{Fundamentação teórica}

\subsection{Modelos de letramento}

Nos anos 90, Soares (1998) define letramento como os saberes adquiridos na imersão no mundo letrado. $\mathrm{O}$ conceito tradicionalmente ou se contrapõe à noção de alfabetização, ou a acompanha, em geral representando um passo além da aquisição da leitura e escrita (SILVA, 2019). Para Kleiman (1995), a noção de letramento considera as relações que o aprendiz tem com uma variedade de práticas de língua(gem) muito antes de aprender a ler e escrever. Por outro lado, a alfabetização, concentra-se exclusivamente na decodificação da palavra escrita. Tfouni (1988, p. 20) compartilha essa visão e afirmar que "Enquanto a alfabetização ocupa-se da aquisição da escrita por um indivíduo, ou grupo de indivíduos, o letramento focaliza os aspectos sócio-históricos da aquisição de um sistema escrito por uma sociedade".

A noção de letramento apresentou novos rumos para o panorama escolar brasileiro. No entanto, por mais que tenha ampliado o ensino de língua materna para além da aquisição da leitura e escrita pela decodificação do signo linguístico, essa noção de letramento, naquele momento, ainda se mostrou muito entrelaçada à ideia de escolarização, igualando inteligência a nível de escolaridade, como argumentam Kleiman (1995) e Soares (1998). A leitura estava

\footnotetext{
${ }^{2}$ Segundo o último relatório do PISA (OCDE, 2016, p. 2), $43 \%$ dos alunos brasileiros estão entre "os $20 \%$ mais desfavorecidos na escala internacional de níveis sócio-econômicos". As baixas condições sócio-econômicas se relacionam ao precário acesso e à exclusão digital no Brasil (MACHADO, 2018).
} 
atrelada ao sucesso escolar e à formação acadêmica. O bom leitor era escolarizado, dotado de conhecimentos da cultura escrita, subordinada a formalismos.

Essa perspectiva restringe a construção do conhecimento linguístico-discursivo a uma ação mecanizada, de troca entre cumprir o currículo escolar e adquirir conhecimento, em que a capacidade cognitiva desenvolve-se exclusivamente com base no acesso ao saber científico: "quanto maior o nível de escolarização, maior o grau de letramento e melhor a performance do indivíduo na comunicação social" (SIGNORINI, 1995, p. 162). Ou seja, entende-se que quanto mais estudada, mais letrada a pessoa é, perspectiva que invariavelmente desvaloriza as vivências fora do ambiente escolar, já que essa equiparação de letramento com escolarização não dialoga com outras formas de saber que não aquele adquirido formalmente na escola.

Para Signorini (1995), essa visão está tão fortemente enraizada nos discursos escolar, acadêmico e profissional das sociedades ocidentalizadas que a ideia de fracasso e de sucesso acaba tornando-se sinônimo de notas boas. A autora explica que "tanto o não-acesso à escola quanto o fracasso escolar são vistos como sinônimos de déficit desses mesmos bens culturais - não ser 'estudado' é ser ignorante" (1995, p. 162). O letramento passa a ser entendido como uniforme, nessa perspectiva, encarado por um ângulo menos inovador, em vez de concebido como um processo dinâmico e diverso (SIGNORINI, 1995).

Nesse sentido, o termo letrado dialoga com uma visão autônoma de letramento e cria uma estreita relação com os níveis de estudo formal. Baseado em uma perspectiva humanista liberal, a visão autônoma prevê o letramento como um conjunto de habilidades necessárias para a atuação em comunidade (CERVETTI; PARDALES; DAMICO, 2001), quase como um item utilitário. Daí provém a ideia do letramento neutro, uniforme e independente do contexto de ensino-aprendizagem (STREET, 1995 [1984], 2003).

Para Costa (2012, p. 920), essa visão autônoma restringe o letramento a um processo “cognitivo individual (e não social), desvinculado de instituições, de contextos culturais e, como consequência, de relações de poder”. Desse modo, acredita-se que se todos indivíduos adquirirem as habilidades necessárias para se tornarem letrados, todos experimentarão efeitos positivos de ordem cognitiva, econômica, profissional, etc. (SOARES, 1998), já que tornar-se letrado é algo que depende exclusivamente de cada pessoa, independentemente dos contextos e históricos de ensino-aprendizagem desses sujeitos.

Diferentemente, Street (1995 [1984]), propõe a noção de letramento ideológico como os conhecimentos de mundo que construímos dentro e fora da escola, valorizando as diversas formas de saber. A visão ideológica vê o letramento não como um conjunto de habilidades, em que a leitura-escrita termina em si mesma (KLEIMAN, 1995), mas como práticas sociais 
que fazem uso de habilidades não exclusivamente oriundas do mundo letrado, construídas de acordo com contextos e relações de poder (STREET, 1995 [1984]), perspectiva que destaca a relação intrínseca entre "as práticas letradas e as estruturas de cultura e poder da sociedade" (COSTA, 2012, p. 920).

Por não considerar uma série de variáveis sociais e bases ideológicos presentes nas interações realizadas nas diversas esferas de atividade humana, dentre elas a escola, a visão autônoma mostra-se insuficiente para uma educação significativa e crítica, como argumentam Street (1995 [1984], 2003), Kleiman (1995) e Soares (1998). Mais especificamente, Kleiman (1995), contrasta os letramentos autônomo e ideológico, em que o primeiro enfatiza a relação letramento-progresso e elege os indivíduos formalmente escolarizados como modelo, o que pode reproduzir preconceitos e/ou criar dicotomias, e o segundo vê as práticas de letramento como culturalmente determinadas, dependentes dos contextos/instituições em que a leitura e a escrita são desenvolvidas.

\subsection{Letramento crítico}

Para discorrer sobre letramento crítico, parece-nos importante primeiro mencionar as reflexões de Bakhtin/Volochinov (2006), para quem a língua(gem) é heterogênea e dialógica, co-construída sócio-historicamente e marcada por ideologias, pois incorpora discursos outros, atualizados pelos sujeitos enunciadores na situação de interação. A visão bakhtiniana localiza a atividade verbal na interação, enfatizando sua natureza sócio-histórica, não neutra, na qual a diversidade discursiva e a assimetria das relações humanas se reflete.

Adotar os pressupostos bakhtinianos significa compreender que tudo o que fazemos com a língua(gem), desde nossa própria constituição como sujeitos do discurso, carrega-se de polifonia. A língua(gem), seja qual for a sua modalidade, é contextualmente construída, não se configurando apenas como um sistema de regras, um conjunto de códigos a ser decifrado ou uma ferramenta de comunicação. A língua(gem) é também uma forma de "emancipação e reconstrução social dos sujeitos, visto que as práticas sociais estão trespassadas por relações sociais desiguais e pelos interesses, poder e influência de grupos dominantes nas sociedades" (SÁ; COSTA, 2018, p. 105).

Esse paradigma dialoga com as ideias de Paulo Freire (1979, 1980, 1987, 2011, 2014) e com sua reflexão sobre letramento crítico, desenvolvida a partir de suas experiências com trabalhadores oprimidos, em áreas rurais no Brasil da década de 70, onde ele percebeu que "a tão somente alfabetização desses sujeitos não seria suficiente para garantir-lhes maior voz e inclusão social" (SÁ; COSTA, 2018, p. 105). Ou seja, a aquisição da leitura-escrita somente, 
na verificação de Freire, não fornecia aos sujeitos-aprendizes os conhecimentos e estratégias que de fato lhes fariam compreender os mecanismos díspares da sociedade. Para o autor, era necessário saber interpretar e questionar não apenas as informações dos textos escritos, como também o que tais informações representavam sócio-historicamente. Mostrava-se igualmente importante ter consciência do papel da cultura letrada nas oportunidades de acesso/ascensão social, especialmente em um país tradicionalmente desigual como o Brasil.

Não é difícil notar que nem somente a alfabetização e nem apenas a educação formal, como se acreditava nos 90, realmente garantiriam uma atuação crítica e (mais) consciente em um mundo construído por práticas letradas envoltas em relações assimétricas de poder. O que as percepções e reflexões de Freire nos mostram é que, sem uma visão crítica, os indivíduos em geral não alcançam uma compreensão mais profunda das assimetrias sociais atravessadas pelas práticas letradas. Ir além da formalização educacional, entendendo-a como processos e produto sócio-históricos, questionando o papel da cultura letrada na perpetuação de práticas desiguais, tornara-se essencial.

Assim, entendemos que é pelo desenvolvimento da consciência crítica, discutida por Freire nas obras de 1979 e 1980, que questionamos e eventualmente podemos transformar a realidade, processo que passa pelas práticas de língua(gem) orais, escritas e/ou multimodais ${ }^{3}$. É pela língua(gem), em sentido mais amplo, que criamos a realidade e que nos entendemos sujeitos, como sustenta Bakhtin/Volochinov (2006). É também por suas práticas que podemos buscar (alguma) libertação contra as relações desiguais, injustas e frequentemente opressoras das sociedades capitalistas pós-industriais.

A ancoragem do letramento crítico nos estudos de Paulo Freire, na teoria crítica social e nas teorias pós-estruturalistas, como explicam Cervetti, Pardales e Damico (2001) e Mattos e Valério (2010) cria mais espaço para se repensar as práticas de ensino, já que considera que nossa habilidade leitora inicia-se muito antes da aquisição e compreensão da escrito. Esse é o entendimento de Kleiman (1995), em sua discussão sobre o letramento pelo viés ideológico. A autora esclarece que o processo de socialização através da leitura e compreensão da palavra escrita, embora essencial, não deve desvalorizar as práticas da oralidade, tal como a leitura de histórias infantis, ou os conhecimentos das sociedades de base predominantemente oral.

A leitura, assim, é concebida como um exercício de constante reflexão crítica sobre as relações dos sujeitos em sua atuação na sociedade. Esse complexo exercício requer perceber as relações entre ideologias e assimetrias sociais, em que a leitura é "um ato de vir a conhecer

\footnotetext{
${ }^{3} \mathrm{Na}$ educação do século XXI, a multimodalidade não deve ser ignorada, especialmente no ensino de línguas. Para uma revisão e discussão do conceito, recomendamos as obras de Kress (2010, 2003).
} 
o mundo (...) e um meio para a transformação social" (CERVETTI; PARDALES; DAMICO, 2001, s.p.). Em outras palavras, ler vai muito além da compreensão semântica-pragmática das informações de um texto e exige um engajamento do leitor com o(s) tema(s) abordados. Esse engajamento, segundo Alexander e Fox (2013, p. 52), refere-se "à participação significativa e direcionada dos alunos na aprendizagem”, em que o texto (escrito, oral ou multimodal) é uma peça ímpar no processo de construção de conhecimentos. Essa concepção de leitura orienta o plano didático a ser apresentado na quarta seção.

\subsection{Letramentos digitais}

As discussões realizadas sobre letramento até o início do século XXI referiam-se às práticas letradas organizadas principalmente na esfera do código escrito. No entanto, após a revolução trazida pelo computador pessoal e pela Internet, em particular, e com o crescente interesse acadêmico pela multimodalidade, falar em letramento sem mencionar as tecnologias digitais tornou-se ultrapassado e insuficiente, especialmente se considerarmos a lacuna entre incluídos e excluídos digitais ${ }^{4}$. Desse modo, como argumentam Dudeney, Hockly e Pegrum (2014, p. 19), as práticas pedagógicas que se focam somente no letramento escrito tendem a "fraudar nossos estudantes no seu presente e em suas necessidades futuras".

Além disso, é sabido que simplesmente adquirir dispositivos digitais, sem saber como utilizá-los de forma crítica e eficaz, não explorando suas affordances ${ }^{5}$, gera pouco impacto na educação (PRENSKY; 2012; PÉREZ-GÓMEZ, 2015). Para Assumpção e Mori (2006, p. 2), a inclusão digital, isto é, a democratização do acesso às tecnologias digitais, envolve a prática de habilidades simples "que vão de tarefas básicas, como escrever e-mails e reconhecer um spam, a atividades complexas, como pesquisar de maneira eficaz, acessar serviços e produzir um vídeo e transmitir via web”. Em última instância, ser letrado digitalmente é poder agir nas esferas virtuais, o que vai muito além de criar uma conta e-mail e envolve novas abordagens à forma como lemos, escrevemos e construímos conhecimento online.

Recomenda-se, portanto, que o currículo escolar e as práticas de ensino contemplem os chamados letramentos digitais, isto é, o conjunto de habilidades necessárias para encontrar e gerenciar uma diversidade de recursos textuais-midiáticos, para expressar ideias e trabalhar colaborativamente na interpretação, compartilhamento e construção de sentido nos ambientes digitais, segundo Dudeney, Hockly e Pegrum (2014). Os autores organizam os letramentos digitais em quatro macroletramentos, quais sejam: pessoal, em jogos, móvel e remix, os quais

\footnotetext{
${ }^{4}$ Segundo Silva, Ziviani e Ghezzi (2019), o perfil de usuário digital eficiente equipara-se ao indivíduo letrado e formalmente instruído, com poder aquisitivo para pagar por serviços e dispositivos tecnológicos/digitais. ${ }^{5}$ Affordances são as possibilidades e limitações que as tecnologias nos oferecem (CONOLE; DYKE, 2004). 
congregam habilidades digitais focadas em linguagem, informação, conexões e (re)desenho, cobrindo desde conhecimentos de letramento impresso (escrito) e de hipertexto a letramento em pesquisa, filtragem e rede.

Seguindo esse raciocínio, podemos entender os letramentos digitais como múltiplos, uma vez que eles pressupõem habilidades variadas, de naturezas diversas. Ler online requer compreender a linguagem verbal-multimodal e interpretar o conteúdo semântico-pragmático, como se faz a leitura de qualquer texto. No ambiente virtual, no entanto, é necessário também saber manipular as tecnologias digitais para acessar e selecionar informações e navegar por hipertextos, filtrando o conteúdo. Ser digitalmente letrado significa saber interagir nas esferas virtuais com eficiência, criticidade e segurança, compreendendo as funções sociais da atuação virtual e das tecnologias digitais.

Os letramentos digitais também podem ser vistos como multimodais e multifacetados. As tecnologias e textos com os quais interagimos online organizam-se em diferentes modos semióticos. Nesse processo, colocamos em prática habilidades adquiridas previamente, mas de forma diferente. Um exemplo é a escrita pictográfica dos emojis. Segundo Mattos et al. (2019, p. 66), a leitura de emojis assemelha-se a ler quebra-cabeças rébus, típicos da Grécia Antiga e da Idade Média, cujo "sentido precisava ser desvendado através da associação entre linguagem verbal e não verbal". Ou seja, parte do que fazemos linguística e textualmente no ambiente online não é de todo inédito: a forma como usamos a língua(gem) e as tecnologias é que pode levar a novos efeitos de sentido.

\section{Considerações sobre a leitura}

\subsection{A leitura em três fases}

A Base Nacional Comum Curricular (BNCC) (BRASIL, 2017) recomenda a leitura abordada em três fases: 1) pré-leitura; 2) leitura; e 3) pós-leitura. Na pré-leitura, que funciona como uma preparação para a leitura do texto, o principal objetivo é criar familiaridade com o tema e o gênero textual do texto a ser lido. Isso pode ser feito com apoio de textos adicionais, como será visto no plano didático, ou pela exploração de elementos da organização do texto, tais como título, subtítulo, autor, imagens etc. O foco é a ativação dos conhecimentos prévios, ou esquemas dos leitores (cf. RUMELHART, 1980).

A segunda fase refere-se à leitura propriamente, ou à interpretação do texto, por meio do engajamento do leitor com seus conteúdos. Os conhecimentos prévios já ativados auxiliam a realização de inferências e a confirmação ou refutação de expectativas, criando associações 
entre informação lida e experiência/conhecimentos do leitor. O "resultado" desse processo é a construção de novos saberes ou o reconhecimento daquilo que já se sabe. É preciso ressaltar o caráter dinâmico do processo de leitura: embora explicado aqui de forma linear, ler não é um ato estático, rigidamente sequencial.

A terceira fase de leitura, por fim, volta-se para um adentramento da interpretação do texto, isto é, uma reflexão mais aprofundada sobre o tema. Concretamente, trata-se de avaliar criticamente os discursos do texto, associando-os a seus contextos de produção e à realidade atual, verificando semelhanças e diferenças. No que diz respeito ao engajamento entre leitor e texto, Alexander e Fox (2013) recomendam a maximização da relação dialógica entre leitura e aprendizado: aprender para ler e ler para aprender. Torna-se importante mostrar ao aluno que a leitura é uma forma de aprendizado, dentro e fora da escola.

Nossa proposta também se ancora nas considerações de Alexander e Fox (2013) sobre a leitura como engajamento, para quem a seleção de temas relevantes e atuais, contemplando diferentes gêneros e níveis de dificuldade de compreensão mostra-se fundamental. As autoras também recomendam elaborar tarefas que promovam o engajamento dos alunos com o texto, desde a etapa de pré-leitura à produção escrita ou falada em pós-leitura, priorizando situações em que os alunos possam assumir um papel central na leitura, tornando-se mais responsáveis pelo seu aprendizado próprio aprendizado.

\subsection{Abordando a leitura online}

Como recomendado em Sá (2017), um diagnóstico das habilidades digitais dos alunos deve ser feito antes de planejar de ações destinadas a desenvolver os letramentos digitais. Em nossos contextos de ensino, por exemplo, isso foi feito por meio de questionário ou discussão no laboratório de informática, com aulas dedicadas apenas a melhor compreender a realidade de acesso/uso de tecnologias digitais dos alunos. Esse diagnóstico é essencial para incorporar as tecnologias digitais e desenvolver as competências de leitura de hipertextos e hipermídias de maneira crítica, tal como indicado na BNCC.

Além disso, os alunos devem ser motivados a sempre identificar as fontes dos textos digitais, buscando evidências que corroborem/confirmem sua autenticidade, como sugerido em Singer e Alexander (2016). Outro ponto de atenção é a tendência ao multitasking digital, o que pode levar a uma leitura superficial do texto, segundo as autoras. Isso pode ser evitado por meio da leitura guiada, em que as perguntas são lançadas antes da leitura, cujas respostas devem ser identificadas durante a leitura do texto, e com tarefas pós-leitura mais centradas em 
habilidades de produção linguística, como, por exemplo, a elaboração de um texto escrito ou uma apresentação oral relacionada ao texto lido ou ao seu tema.

Na prática da leitura online, o professor tem o papel de orquestrar a aprendizagem dos alunos (LEU et al, 2017), orientando-os sobre como melhor utilizar as tecnologias digitais, o que exige um desenvolvimento de seus próprios letramentos digitais, além de familiaridade com as tecnologias que deseja/precisa incorporar à prática de ensino. Essa é uma observação importante. Como reportado em Mattos, Echenique e Oliveira (2019) e Sá (2018), a formação de professores, inicial e continuada, tem se mostrado como um espaço para o aprimoramento de habilidades tecnológico-digitais, visto que, nos estudos realizados pelas autoras, a maioria dos docentes não demonstrou ter conhecimentos suficientes para abordar a leitura online com seus alunos.

\section{Plano didático}

Para colocar em prática as observações até o momento tecidas, este trabalho apresenta um plano didático para o desenvolvimento da leitura crítica em língua materna. Guiada pelas reflexões sobre letramento crítico e letramento digitais, como previamente discutidas, o plano didático tem como principal tema a exclusão digital no Brasil, assunto de importância para a atuação social crítica dos aprendizes no século XXI. A escolha desse tema justifica-se como uma forma de abordar os letramentos digitais, considerando que a função da escola é ampliar os conhecimentos digitais dos aprendizes (BUCKINGHAM, 2010).

Direcionado à segunda série do Ensino Médio, para ser aplicado nas aulas de leitura e produção de textos, o plano didático configura-se como um exemplar de prática de ensino de habilidades comunicativas integradas. Isso quer dizer que o trabalho com a leitura não se faz somente por atividades de leitura e compreensão de textos, mas também por tarefas de fala, escuta e escrita, aproximando-se mais da realidade interacional cotidiana, em que estamos em contato e fazemos uso de diferentes formas de organizar nossos projetos de dizer. Ancorado principalmente no texto de Caribé (2012), o plano didático cobre o período de duas aulas de 50 minutos.

\section{Apresentação do tema}

1. Observe a imagem abaixo. Em pares, discuta:

a) O que essa imagem retrata?

b) A qual região geográfica ela se refere?

c) Como você chegou a essas conclusões? 


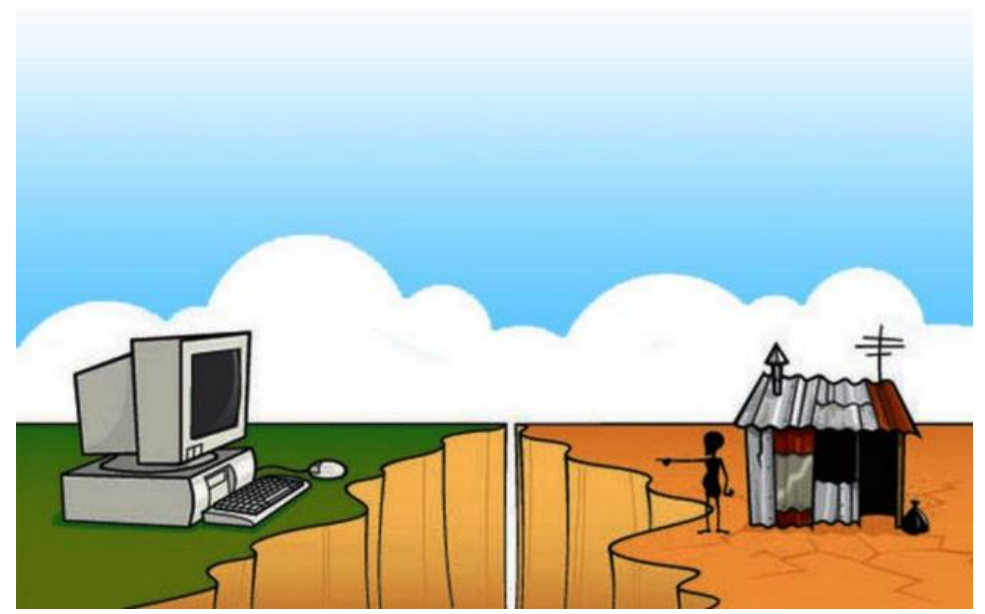

Fonte: reproduzido de Machado (2018)

\section{Pré-leitura}

2. Assista às reportagens da TV Unesp e da TV Minas e tome nota sobre:

a) As principais razões da exclusão digital no Brasil;

b) As iniciativas de inclusão digital no país.

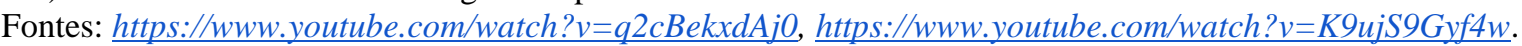

\section{Leitura}

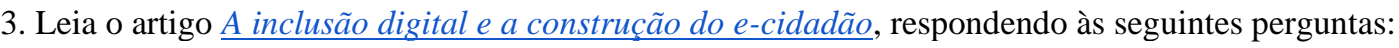

a) Qual a associação que Caribé faz entre a revolução digital e o choque de gerações?

b) $\mathrm{O}$ que o autor quis dizer com "grandes fatos recentes noticiados pela mídia mainstream foram antes noticiados pela mídia mystream"? Você consegue pensar em um exemplo disso?

c) Associe as informações reportadas nos vídeos com os dados do texto, pensando em como os dados sobre acesso às tecnologias são apresentados no artigo e nas reportagens. Discuta as diferenças e as semelhanças. Por que isso acontece?

\section{Pós-leitura}

4. Em grupos de até quatro participantes, discuta as afirmações abaixo e faça as tarefas que se seguem.

a) Para Caribé, a internet democratizou o acesso ao conhecimento e à produção cultural e intelectual, e segue criando novas formas de relacionamentos. Dê exemplos e comente como a internet ou as tecnologias digitais contribuíram para a democratização do conhecimento, produção cultural ou produção intelectual no Brasil ou, mais especificamente, na sua experiência pessoal.

b) $\mathrm{O}$ autor afirma que "temos claramente a construção de um quinto poder, que é a sociedade organizada e conectada (e-cidadania), [...] os e-cidadãos". Você se vê como um e-cidadão? Por quê?

\section{Expansão do tema}

5. Em grupos, elabore um plano de ação para promover a inclusão digital em seu bairro, região ou município.

Sugestões:

- Analise a infraestrutura/serviços tecnológicos oferecidos à população. Exemplos:

○ Há wi-fi gratuito na região? Funciona bem? Qual a velocidade? É fácil de acessar?

○ Há centros que oferecem acesso gratuito a computadores com internet?

○ E nas escolas? Como é feito o acesso à internet?

- Teste a infraestrutura/serviço, tomando notas. Faça um breve relatório sobre os pontos positivos e o que pode melhorar. Inclua imagens e dados, se possível.

- Identifique os órgãos responsáveis pela infraestrutura/serviço e pelos problemas mapeados.

- Quais grupos sociais são mais afetados pelos problemas identificados? Justifique como esses grupos podem se beneficiar com a iniciativa e qual a importância da proposta para a inclusão digital. 
O plano didático começa com uma apresentação ao tema, centrada na figura do texto de Machado (2018) sobre exclusão digital. O texto, embora não incorporado à proposta, pode ser incluído, a depender do cronograma de ensino, uma vez que traz dados importantes sobre o (não) acesso às tecnologias digitais no Brasil. Tecnicamente, a apresentação do tema pode ser entendida como parte da pré-leitura, tal como prevista pela BNCC. Neste plano didático, e por motivações didáticas, optamos por visualmente organizá-la separadamente, visto que esta apresentação concentra-se mais em introduzir o assunto geral do texto do que questões mais pontuais de seu conteúdo. O modo semiótico privilegiado é a imagem estática.

A pré-leitura deste plano didático, por sua vez, envolve o modo semiótico da imagem dinâmica confluente a outros modos, como é típico do texto televisivo, considerado complexo e híbrido (ENERIM, 2000). Além de fazerem uso da fala formal, as reportagens lançam mão de recursos imagéticos para facilitar a veiculação das informações. A escolha por reportagens disponíveis gratuitamente no YouTube propicia flexibilidade ao professor, que pode conduzir a aula no laboratório de informática ou não, optando por salvar os vídeos em formato MP4, sem precisar de conexão à internet. Isso pode especialmente útil para escolas que dispõem de infraestrutura mais limitada.

As reportagens selecionadas trazem dados e ações de inclusão digital, preparando os alunos para a leitura do texto principal e para a expansão do tema, que compõe a fase final do plano. Os dados de 2017 podem ser contrastados com os de 2012, do texto de Caribé, ou com o ano de aplicação da atividade, para identificar alguma mudança no intervalo. Além disso, a própria situação de acesso digital dos alunos pode ser discutida com base nas informações das reportagens, como autorreflexão. Por serem relativamente curtas, com cerca 4 minutos cada, as reportagens podem ser revistas sem interferir com as demais atividades do plano didático.

Para incentivar o engajamento, sugerimos a leitura guiada do texto, começando pelas perguntas a e b da questão 3 , que objetivam a compreensão de pontos centrais do $\operatorname{artigo~}^{6}$. As expressões metafóricas (nativos/imigrantes digitais, teia global, etc.) podem ser exploradas antes da primeira leitura e observações acerca do conteúdo do texto podem ser feitas para que o professor averigue o nível de entendimento dos alunos em relação a afirmações/expressões mais técnicas, como "A teia global agora é uma colmeia global, onde a construção coletiva e cognitiva [...] está formando a Inteligência Coletiva" e "Este novo ecossistema social deu voz aos excluídos".

\footnotetext{
${ }^{6}$ Por ser um artigo relativamente longo, com 1.850 palavras, pode ser necessário reduzi-lo. Sugerimos a retirada da subseção "A construção do e-cidadão", com 775 palavras, que apresenta dados adicionais e é mais técnica. Sua eliminação, em nosso entendimento, não compromete a compreensão das principais ideias do texto.
} 
Para a segunda leitura, a forma como os dados foram apresentados no artigo pode ser contrastada com a maneira pela qual as reportagens comunicam as mesmas informações, com o objetivo de entender como diferentes modos semióticos influenciam a construção textual e os efeitos de sentido. Por exemplo, como os números são comunicados nas reportagens e no texto de Caribé? Os exemplos de inclusão social são expostos da mesma maneira? Perguntas dessa natureza exigem que os alunos retornem ao texto para melhor entender seus elementos textuais e fazem com que eles pensem sobre como a disposição e as escolhas de língua(gem) contribuem para a comunicação de ideias e a argumentação.

A fase de pós-leitura do plano didático tem o intuito de levar os alunos a refletir sobre a inclusão digital no Brasil, buscando evidências (exemplos concretos) de como a internet ou as tecnologias digitais contribuíram para a democratização e o acesso à informação no País. Essa fase pode ser desenvolvida em grupos tanto em sala de aula quanto como tarefa de casa. É importante, no entanto, que haja troca de experiência entre os alunos e que, coletivamente, eles consigam coletar e comentar exemplos dos benefícios democráticos da inclusão digital, os quais podem ser comunicados em formato de apresentação oral.

Por fim, o plano didático oferece aos alunos a possibilidade de colocar em prática os conhecimentos construídos pela leitura e discussão dos textos propostos, especificamente em relação à inclusão digital. Ao sugerir que os alunos elaborem um plano de ação voltado para a realidade local, espera-se que os aprendizes examinem seus contextos sociais e reflitam sobre as condições de acesso às tecnologias, avaliando criticamente a infraestrutura e/ou os serviços oferecidos à população local. Para tanto, será necessário que os alunos adotem uma postura inquisitiva na inspeção do contexto local e nas buscas online, que eventualmente serão feitas para dar suporte à elaboração da proposta, indiretamente desenvolvendo habilidades de busca e seleção de informações.

Sugestões para desenvolvimento do plano de ação foram incluídas, são opcionais e podem ser ajustadas. Seu objetivo, no entanto, é auxiliar e orientar os alunos na tarefa prática de investigação da infraestrutura e/ou serviços tecnológicos locais. Os exemplos dados devem ser tomados como ilustrativos, isto é, não têm o propósito de tirar o protagonismo dos alunos ou limitar suas ideias. A expectativa é que, ao trabalhar em pequenos grupos, os aprendizes dialoguem e tenham ideias diversas, o que pode ser bastante enriquecedor para uma discussão sobre as iniciativas em sala de aula ou mesmo para uma apresentação dos planos de ação para outras séries do Ensino Médio.

Dos letramentos digitais pressupostos por Dudeney, Hockly e Pegrum (2014), o plano abarca o letramento impresso, multimídia, participativo, em hipertexto, pesquisa, informação 
e filtragem, nos eixos dos macroletramentos de linguagem, informação e conexões. O nível de dificuldade desses letramentos é intermediário, segundo os autores, o que quer dizer que, a depender do contexto, o professor pode ajustar as tarefas à capacidade de seus alunos, seja ao adicionar outros letramentos ou ao calibrar o grau de "proficiência” necessário para cumprir o plano didático.

\section{Conclusão}

Como refletido, usar a língua(gem) de forma eficaz depende em grande parte do nível de letramento de um indivíduo, isto é, dos conhecimentos linguístico-discursivos construídos pela imersão nas práticas de língua(gem), o que inclui, mas não se limita, ao mundo letrado da escrita. Conhecimentos adquiridos e relacionados à oralidade e a outros modos semióticos são igualmente importantes para a formação letrada e para a atuação social, especialmente na atualidade, em que as tecnologias digitais oferecem possibilidades renovadas de interação.

Quando nos distanciamos da imagem do indivíduo formalmente escolarizado como o detentor único do saber, redistribuímos os papéis sociais e as relações de poder. Na dinâmica escolar, isso implica entender e valorizar os saberes que os alunos trazem para a sala de aula, ao mesmo tempo, buscando ampliar seus horizontes e suas possibilidades de atuação social e acadêmica, especialmente em referência ao acesso e uso eficaz das tecnologias digitais. Nessa esteira, as práticas de ensino atuais exigem que o professor vá além do letramento tradicional escrito (DUDENEY; HOCKLY; PEGRUM, 2014).

Com o presente texto esperamos oferecer a pesquisadores e professores experientes e novatos reflexões sobre concepções e práticas de letramento. Esperamos que o plano didático sugerido seja útil para o ensino-aprendizagem de habilidades de leitura, particularmente por abordar o tema da exclusão digital de forma contextualizada e por oferecer flexibilidade para adaptações a diferentes realidades e contextos de ensino.

\section{Referências}

ALEXANDER, P. A.; FOX, E. A historical perspective on reading research and practice. In ALVERMANN, D. E.; UNRAU, N. J.; RUDDELL, R. B. (Eds.) Theoretical models and processes of reading. International Reading Association, 2013, p. 1-46.

ASSUMPÇÃO, R.; MORI, C. Inclusão digital: discursos, práticas e um longo caminho a percorrer. In KNIGHT, P.; FERNANDES, C.; CUNHA, M. A. (Orgs.) E-Desenvolvimento no Brasil e no mundo: subsídios e programas e-Brasil. São Paulo: Yendis, 2007.

BAKHTIN/VOLOCHINOV, M. Marxismo e Filosofia da Linguagem. SP: Hucitec, 2006. BRASIL. PISA 2015. Resultados da avaliação. Brasília: INEP/MEC, 2016. Disponível em: http://inep.gov.br/web/guest/acoes-internacionais/pisa/resultados. Acesso: 5 out 2019. 
BRASIL. Base Nacional Comum Curricular. Brasília: MEC/CNE, 2017. Disponível em: http://basenacionalcomum.mec.gov.br/. Acesso: 5 out 2019.

BUCKINGHAM, D. Cultura digital, educação midiática e o lugar da escolarização. Educação \& Realidade. Porto Alegre, v. 35, n. 3, p. 37-58, 2010. Disponível em: https://seer.ufrgs.br/educacaoerealidade/article/view/13077. Acesso: 5 out 2019

CARIBÉ, J. C. R. A inclusão digital e a construção do e-cidadão. Revista Fórum, 09/02/12. https://revistaforum.com.br/revista/100/a-inclusao-digital-e-a-construcao-do-e-cidadao/.

Acesso: 4 abril 2018.

CONOLE, G.; DYKE, M. What are the affordances of information and communication technologies? Research in Learning and Technology, v. 12, n. 2, 2004. Disponível em: 10.1080/0968776042000216183. Acesso: 15 ago 2018.

CERVETTI, G.; PARDALES, M. J.; DAMICO, J. S. A tale of differences: comparing the traditions, perspectives, and educational goals of Critical Reading and Critical Literacy. Reading Online, v. 4, n. 9, 2001.

COSTA, E. G. M. Práticas de letramento crítico na formação de professores de línguas estrangeiras. Revista Brasileira de Linguística Aplicada - RBLA, v. 12, n. 4, p. 911-932, 2012. Disponível em: 10.1590/S1984-63982012000400012. Acesso: 5 out 2019.

DUDENEY, G.; HOCKLY, N.; PEGRUM, M. Digital Literacies. New York: Routledge, 2014.

FREIRE, P. Educação e mudança. 12 ed., Rio de Janeiro: Paz \& Terra, 1979.

FREIRE, P. Conscientização: teoria e prática da libertação. 3 ed. São Paulo: Moraes, 1980.

FREIRE, P. Pedagogia do oprimido. 17 ed., Rio de Janeiro: Paz \& Terra, 1987.

FREIRE, P. Educação como Prática de Liberdade. 14 ed., São Paulo: Paz \& Terra, 2011.

FREIRE, P. Pedagogia da Autonomia: saberes necessários à prática educativa. 51 ed., São Paulo: Paz \& Terra, 2014.

KLEIMAN, A. B. Texto e leitor: aspectos cognitivos da leitura. Campinas: Pontes, 1995.

KRESS, G. Multimodality. A social semiotic approach to contemporary communication. New York: Routledge, 2010.

KRESS, G. Literacy in the New Media Age. New York: Routledge, 2003.

LEU, D. J. et al. New literacies: A dual-level theory of the changing nature of literacy, instruction, and assessment. Journal of Education, v. 197, n. 2, p. 1-18, 2017. Disponível em: 10.1177/002205741719700202. Acesso 25 ago 2019.

MACHADO, J. B. M. Exclusão digital no Brasil. Blogue Consumidor Cidadão. 30/07/18. https://consumidorcidadao.wordpress.com/2018/07/30/exclusao-digital-no-brasil/. Acesso: 10 ago 2018.

MATTOS, A. M. A.; VALÉRIO, K. M. Letramento crítico e ensino comunicativo: lacunas e interseções. Revista Brasileira de Linguística Aplicada - RBLA, v. 10, n. 1, p. 135-158, 2010. Disponpivel em: http://www.scielo.br/pdf/rbla/v10n1/08.pdf. Acesso: 22 jul 2018.

MATTOS, E.; BRASIL, V.; GARCIA, G.; OLIVEIRA, N. Emojis e Hashflags: uma análise sóciorretórica da linguagem multissemiótica do Twitter. Leitura, Maceió, n. 63, p. 47-69, jul./dez, 2019. Disponível em: 10.28998/2317-9945.2019n63p47-69. Acesso: 5 out 2019.

MATTOS, E.; ECHENIQUE, M. T.; OLIVEIRA, N. O uso do padlet em um curso de licenciatura em letras. IV Congresso de Inovação e Metodologias no Ensino Superior, 2019. Disponível em: https://congressos.ufmg.br/index.php/congressogiz/IVCIM/paper/view/882. Acesso: 5 out 2019.

OCDE. Brasil - Resumo de resultados nacionais do PISA 2015. 2016. Disponível em: http://download.inep.gov.br/acoes_internacionais/pisa/resultados/2015/pisa_2015_brazil_prt.p df. Acesso: 12 out 2019.

PÉREZ GÓMEZ, Á. Educação na era digital: a escola educativa. Porto Alegre: Penso, 2015. PRENSKY, M. From digital natives to digital wisdom. California: Corwin, 2012. 
RUMELHART, D. E. The Building Blocks of Cognition. In SPIRO, R. J.; BRUCE, B. C.; BREWER, W. (Orgs.) Theoretical Issues in Reading Comprehension. Hillsdale: Lawrence Erlbaum Assoc, 1980, p. 33-58.

SÁ, E. M. Netspeak e emojis na formação continuada de professores de inglês. In ORLANDI, E. et al. (Orgs.) ENELIN 2017 - textos completos. Pouso Alegre: Univás, 2018. Disponível em: http://pos.univas.edu.br/ppgcl/docs/2017/anais-2017.pdf. Acesso: 1 ago 2018. SÁ, E. M.; COSTA, E. J. PLAc, abordagem comunicativa e letramento crítico: pontos de convergência para a inclusão de práticas digitais no contexto brasileiro de ensinoaprendizagem. Letras \& Letras, v. 34, n. 1, p. 95-121, 2 jul. 2018. Disponível em: https://doi.org/10.14393/LL63-v34n1a2018-5. Acesso: 12 out 2019.

SIGNORINI, I. Letramento e (in)flexibilidade comunicativa. In KLEIMAN, A. (Org.) Os significados do letramento: uma nova perspectiva sobre a prática social da escrita. Campinas: Mercado de Letras, 1995, p. 161-199.

SILVA, F. A. B.; ZIVIANI, P.; GHEZZI, D. As tecnologias digitais e seus usos. Texto para discussão. Instituto de Pesquisa Econômica Aplicada - IPEA. Brasília/Rio de Janeiro, 2019. Disponível em: http://www.ipea.gov.br/portal/images/stories/PDFs/TDs/td_uuu2470.pdf.

SILVA, W. R. Polêmica da alfabetização no Brasil de Paulo Freire. Trabalhos em Linguística Aplicada, v. 58, n. 1, p. 219-240, 17 abr. 2019. Disponível em: https://periodicos.sbu.unicamp.br/ojs/index.php/tla/article/view/8654598. Acesso: 5 out 2019.

SINGER, L. M.; ALEXANDER, P. A. Reading Across Mediums: Effects of Reading Digital and Print Texts on Comprehension and Calibration. The Journal of Experimental Education, v. 85, n. 1, p. 155-172, 2016. Disponível em: 10.1080/00220973.2016.1143794. Acesso: 5 out 2019.

SOARES, M. Letramento: um tema em três gêneros. Belo Horizonte, MG: Autêntica, 1998. STREET, B. What's "new" in New Literacy Studies? Critical approaches to literacy in theory and practice. Current Issues in Comparative Education, v. 5, n. 2, p. 77-91, 2003. Disponível em: https://www.tc.columbia.edu/cice/pdf/25734_5_2_Street.pdf. Acesso em: 21 ago 2019.

STREET, B. Literacy in theory and practice. New York: Cambridge University Press, 1995 [1984].

TFOUNI, L. V. Adultos não alfabetizados: o avesso do avesso. Campinas: Pontes, 1988. 